\title{
Assemblages and scale in archaeology
}

Oliver J. T. Harris

\section{Abstract}

The growing interest in assemblages has already opened up a number of important lines of enquiry in archaeology from the morphogenetic capacities of matter through to a rethinking of the concept of community. In this paper I want to explore how assemblages allow us to reconceptualise the critical issue of scale. Archaeologists have vacillated between expending energy on the 'great processes' of change like the evolution of humanity, the colonisation of the globe or the origins of agriculture, and focussing on the momentary, fleeting nature of a small-scale ethnographic present. Where archaeologists have attempted to integrate different scales the result has usually been to turn to Annales influenced or time perspectivism-driven approaches and their fixed, linear, and ontologically incompatible layers of history. In contrast, I will use assemblages to examine how we can rethink both the emergence of multiple scales, and their role in history, without reducing the differences of the small-scale to an epiphenomenal outcome of larger events, or treating large-scale historical processes as mere reifications of the 'real' on-the-ground stuff of daily life. As we will see, this approach also has consequences for the particular kind of reality we accord to large-scale archaeological categories.

\section{Introduction}

Assemblages are a powerful tool for reconceptualising the world around us, for opening up new kinds of questions, and for challenging some of the ontological assumptions on which archaeology rests. They have recently been employed to re-evaluate all sorts of elements of our discipline, from the nature of our pedagogy in the present (e.g. Cobb \& Croucher 2014), via the kinds of affective experiences generated by particular encounters in the present or the past (Hamilakis 2014) and the worlds of medieval pottery (Jervis 2014), to the very nature of archaeology and archaeological practice (e.g. Fowler 2013; Lucas 2012; Witmore 2014), to give just a few examples. They have also been influential on my own work in a number of areas (Harris 2013; 2014a; 2014b; 2016a; 2016b; forthcoming). One of the strengths of assemblages that has so far only been discussed in passing, however, is the way they work at multiple scales, from an atom all the way up to a galaxy; from the act of typing on a keyboard to the development of the internet. In this paper I will explore this issue in more detail. How do assemblages allow us to rethink the issue of scale in archaeology, and how do they allow us to develop new ways of conceptualising the interaction of multiple scales in the past?

To examine this, I will begin by briefly reviewing some of the different ways in which archaeologists have tended to think about scale. I argue, in parallel to other recent approaches (e.g. Robb \& Harris 
2013; Robb \& Pauketat 2013) that any attempt to privilege a single scale of analysis is inevitably reductionist. I then turn to assemblages to explore how they work at multiple scales. As defined below, assemblage theory begins with a flat ontology (DeLanda 2002), so that whilst different scales of analysis exist, we do not need to accord particular status to any one of these, or indeed to presume radically different rules are at play. Having set out the multi-scalar nature of assemblages, I will examine a case-study working up in scale from a single pot to an entire archaeological period. Fundamentally, as we will see, these different scales are not entirely separate, but are rather integrated within assemblages. This in turn identifies new ways of thinking about archaeological categories as neither externally imposed reifications nor simply internally defined essential historical truths.

\section{Scale in archaeology}

Whilst space prevents a detailed review of different archaeological approaches to scale (for a full analysis see Robb and Pauketat 2013), it is necessary to make a few points in order to place what assemblages can offer in a proper context. Few archaeologists would deny that the past can be thought about at different scales and that different questions come into focus depending upon the analytical lens employed. Clearly archaeologists have access to both moments of astounding intimacy, such as a burial of a child, and processes that last millennia, like the development and spread of agriculture. Yet as Robb and Pauketat (2013) have shown, the reality is actually more complicated than this. The spread of agriculture is on the one hand a long-lasting process, yet on the other the result of specific people, plants and animals doing new things in new ways in new places (Robb 2013). Similarly, the burial of a child may tell us about moments of grief and trauma, but it also depends upon understandings of age, the body and death, which form and transform over millennia (Robb \& Harris 2013). Thus paying attention solely to either the large- or the small-scale will inevitably prove to be insufficient (DeLanda 2006; Robb \& Harris 2013; Robb \& Pauketat 2013). The critical point, therefore, is that archaeologists have to work at multiple scales of analysis to really engage with the historical issues we face, whether we are interested in moments of bereavement or wide-ranging economic change (Robb \& Pauketat 2013).

Of course this has long been known to archaeologists influenced by both the Annales historians in general (e.g. Knapp 1992), and the specific development of time perspectivism by Geoff Bailey (1981; $1987 ; 2007)$. Both of these approaches have emphasised that the past runs simultaneously at different scales. The Annales historian Fernand Braudel (1972) famously divided these scales into short-term events, medium-scale currents and the larger scale of longue durée. In time perspectivism on the other hand, Bailey $(2007,202)$ argues that the scales should be determined by the question under 
consideration. Yet in both cases the relationships between scales is under-investigated and one is left with the distinct impression that what matters is the long-term (Robb \& Pauketat 2013, 12). Indeed critically, as Jan Harding $(2005,95)$ has pointed out, the way Braudel's approach has been interpreted runs the risk of placing the structure of history outside of the processes that produce it, making the differing scales transcendent and eternal, rather than imminent to the activities that form themii.

Multi-scalar archaeology needs to do better, and two recent approaches suggest useful ways forward. John Robb has developed the concept of multiple scales ranging from individual agency, via concepts of tradition through fields and landscapes of action, to historical ontologies (Robb 2008; 2012; 2013). These interact in a non-deterministic fashion and allow us to think about the past in ways that do not reduce either the large-scale to an amalgam of the small, or the small-scale to mere epiphenomena generated by the large. I have found these to be enormously productive, and in many ways compatible with elements of assemblage theory as discussed below (see for example Robb \& Harris 2013, 223). Yet the range of these terms can prevent us from detecting the shared ontological structure that underlies them, and can suggest that radically different types of process operate at different scales. This is problematic, as Andrew Jones $(2012,36)$ has argued, not because all processes are in fact the same, they clearly are not as we will see, but rather because it suggests the differences between processes at different scales is absolute rather than relative. That they differ not only in form, that is, but also ontological status. Therefore a more consistent philosophical basis can provide a firmer foundation for these kinds of analyses. The second approach is Timothy Pauketat's notion of bundling (2013a; 2013b) $)^{i i i}$. Drawing on the archaeology and oral histories of Native Americans, Pauketat has examined how their worlds centre around bundles that operate at multiple scales, from an individual's medicine bundle to the way in which a site like Cahokia bundles together people, time and the cosmos (Pauketat 2013a). Undoubtedly the notion of bundling allows Pauketat (2013a) to develop a transformational narrative of historical and religious change. Furthermore, it has much in common with ideas of assemblage, not least in its emphasis on becoming, the role of non-humans and in its ability to deal with multiple scales (e.g. Pauketat 2013b, 39). Yet at the same time I am not sure that adopting another culturally specific approach and applying it to the period and place I study (Neolithic Europe) will necessarily be helpfuliv. Given that I am not working in a Native American context, we need an approach that offers the potential to think through these ideas without importing other cultural connotations. Thus in contrast to Pauketat's notion of bundling, I propose to pick up the challenge laid down by Chris Gosden $(2013,207)$, who notes that the work of Gilles Deleuze has much to offer archaeologists in thinking about multiple scales, and use this as a provocation to explore these issues through assemblages. 


\section{Assemblages at multiple scales}

\section{What are assemblages?}

It is my contention that assemblages can offer us a multi-scalar approach to the past that offers a robust ontology and neither requires us to work with pre-determined scales, nor asks us to import an external analogue. Before setting out this argument in detail, however, it is worth taking a moment to offer a clear definition of what I mean by the term assemblage as it can be used by different authors in a variety of ways.

Assemblages in their most basic definition are 'compositions that act' (Due 2002, 132). Made up of more or less heterogeneous components, they are gatherings that act back on, but do not totally define, their constituent parts. This means that parts can be detached from one assemblage and included in another without totally transforming the part itself - this is what DeLanda $(2006,10)$ calls relations of exteriority. For Deleuze and Guattari (2004, 97-8; cf. Dewsbury 2011) assemblages are defined along two different axesv ${ }^{v}$. The first axis captures how assemblages always contain both material and expressive elements, that is they are not limited simply to physical components but can include signs, gestures, symbols and all sorts of other elements too. This means that when we embrace assemblage theory there is no reason to reject meaning, identity, or emotion from our archaeological vocabulary, as some readings of new materialist or symmetrical archaeology would suggest we should (Lucas 2012; Olsen et al. 2012). The second axis describes how these compositions are always coming together (territorialising) and breaking apart (deterriorialising) (Deleuze \& Guattari 2004, 98) vi. Thus assemblages are never fixed but always becoming. In turn, working with assemblages is not simply about describing them at one particular moment - as in some of the more static descriptions associated with actor-network-theory - but rather concentrating on process, to be precise on the specific historical process through which an assemblage emerges. Because we attend to historical processes, we can treat the laying down of geological strata by a river in the same manner we might treat the evolution of a particular species: as certain acts of territorialisation operating in a particular kind of way on certain more or less heterogeneous components (DeLanda 1997). We must also embrace the morphogenesis inherent in matter, the way seemingly inanimate elements of the world have particular tendencies, form certain kinds of shapes in certain circumstances (crystals, curves, bubbles) and how these play a vibrant role in the emergence of particular kinds of assemblage (Bennett 2010; DeLanda 2002; 2007; Harris 2014b). 'A life proper to matter' as Deleuze and Guattari $(2004,454)$ put it. 
I argue that assemblages, as part of a wider turn towards Deleuzian thought, offers archaeology a series of advantages. To begin with, as mentioned above, it is rooted in a flat ontology (DeLanda 2002). That means it does not take a particular aspect of the world, like human beings, and presume they occupy a radically different ontological level to the rest of existence, its embrace of the vibrancy of matter welcomes a host of actors onto the historical stage, and rescues them from the wilderness created by our traditions of human exceptionalism. Nor does it suppose that the world can be divided into simple opposed categories be they culture and nature, organic and inorganic, biological and geological. It therefore continues the progress made by archaeologists in the last twenty years in attempting to extricate ourselves from the Cartesian dualisms now widely recognised as being - to put it mildly - problematic (Harris forthcoming). This escape from dualisms also applies to that between science and the arts or between data and interpretation (Harris 2014b). Second, its emphasis on process means that we have to attend to history and its development; it is not merely an attempt to describe the past better (though this is not a bad thing in itself). It therefore does not steer us away from asking critical historical questions. Third, and finally, assemblage based approaches are not simply non-representational, but rather more-than-representational (Harris forthcoming). Whilst post-processual archaeology may have been 'hyper-interpretive' at times (Garrow 2013), an approach based in assemblages does not exclude the importance of meaning, belief, desire or emotion (Harris 2013; 2014b; 2016b; forthcoming). Rather it resituates these elements in a more nuanced and sophisticated ontology.

Demonstrating all of these benefits would take some considerable time, and the references above will hopefully guide a doubtful reader to other publications where these arguments have been made in a more sustained fashion. Rather than simply revisit these debates here, though, I want instead to focus on what assemblages can offer us with regard to archaeological questions around scale.

\section{Assemblages at different scales}

One of the great advantages when it comes to dealing with assemblages and the issue of scale is that it allows us to treat different levels of analysis in the same ontological fashion (Jervis 2014, 24). We can treat an individual hydrogen atom as an assemblage of quarks, and water molecules as assemblages of two hydrogen atoms and an oxygen atom, just as we can treat a lake of water as an assemblage. The latter is obviously far more complicated as it includes not only water molecules but also minerals dissolved in the water swept in from a river that flows in and out of the lake, plants of various kinds, fish and the otters that prey on the fish and so on (each of which is of course also an assemblage). Similarly we can treat individual people as an assemblage - of bones, flesh, cultural dispositions, needs, desires, intentions, and memories and so on - and equally we can treat entire 
communities as such too. Here the assemblage is made up of people of course, but also plants, houses, animals of various kinds, institutions, rules and so on (Harris 2014a). This means that all assemblages are in themselves made up of other assemblages (DeLanda 2016). In every case each of these assemblages has a specific historical process - Deleuze $(2004,307)$ would call it individuation - that brought it into being, for example the nucleosynthesis in a star that formed the oxygen atom, or the geological process that formed the lake bed. Furthermore, just as assemblages are made up of other assemblages - they are in themselves multi-scalar - so are the processes that lead to them. So the lake and its inhabitants discussed above were formed through a process that can be divided into subprocesses we can gloss as geological and biological, and the (more-than-human) community formed through a range of geological/biological/historical developments (DeLanda 1997; 2002; 2006; 2016). Thus rather than arguing we need to understand historical processes as operating differently at various scales, as with time perspectivism (Bailey 2007, 200), we can instead use the same ontological approach to understand how entities at different scales emerged in the past. How might this work in an archaeological setting?

\section{Multiple scales of archaeology}

To explore this I want to look at a specific set of archaeological assemblages that form part of Neolithic Britain, the first period of farming in that country. This dates from c. $4100-2500 \mathrm{cal}$ BC, and is marked by the presence of pottery and domesticated plants and animals for the first time, and the construction of different kinds of monuments (Thomas 2013; Whittle 2003; Whittle et al. 2011). Rather than start with this larger scale of assemblage, however, I want to begin with a single artefact, and we will then work our way back up to the archaeological period as a whole.

The artefact I want to start with is a single Neolithic pot, known variously today as either P2307 or M79 (fig. 1). This pot has featured strongly in a number of archaeological narratives (e.g. Harris 2005; Pollard 2008; Pryor 1998; 2014), because of its context (or rather its wider assemblage cf. Alberti \& Jones 2013, 27-30) as we will see below. Pots are a useful object to think about because they lend themselves well to ideas of assemblage. Pottery is made from clay, temper and hands coming together, the latter mixing the former together, shaping and coiling the mixture into the right shape. Our specific pot here was assembled with fine shell used as temper, presumably brought from elsewhere (Kinnes 1998, 167). It was shaped into a round based bowl with an internal diameter of about $11 \mathrm{~cm}$ and a rolled over rim decorated with incised diagonal decoration (Kinnes 1998, 167). This shows that another element was temporarily part of this assemblage as a tool would have been used 
to create these incisions. These incisions are one part of what Deleuze and Guattari $(2004,98)$ would refer to as the enunciative element of the assemblage, a way in which it can reach out and communicate with the world around it, in this case both with contemporary people and with the archaeologists who would encounter it in years to come ${ }^{\text {vii. }}$

Figure 1: Pot M79 (after Pryor 1998, 170, fig. 181)

Having been shaped in this way the pot was fired, making it temporarily part of another assemblage involving wood of different kinds, flint to strike sparks and perhaps other pots that were fired alongside it. Following that process, the pot may have been used for a while, perhaps to hold milk, or to cook meat. At this scale, the pot acts to bring these different relationships together, and to gather substances that link particular places, animals and people together. It emerged as a result of a specific historical process - the making of this Early Neolithic pot, and the acts of creation and consumption that were caught up in this. Critically, approaching this assemblage as a historical process means we have to assign creativity across the different materials that make it up, from the clay which allows itself to be shaped, to the shell that alters the property of the clay, to the cows that provided the milk, and the ability of the milk to nourish and sustain human beings (Harris 2014b). Here we see the importance of what materials bring to the process, their capacity for morphogenesis noted earlier. The role of the potter here as a key element bringing these together should not be ignored, but nor does it need to take ontological primacy. Agency here does not 'belong' to any one element but is emergent and relational, it is immanent in the coming together of the assemblage.

Figure 2: Section 7 deposits including pot M79 (marked as B2307) (after Pryor, 1998, 33, fig. 30)

The pot is already reaching out, here, to larger scale assemblages. At the end of its use-life this continued as the pot was incorporated into another assemblage, a series of objects deposited along the bottom of a ditch (numbered ditch segment 7) at the causewayed enclosure of Etton, in Cambridgeshire (fig. 2) (Pryor 1998, 33), dug sometime around 3700 cal BC (Whittle et al. 2011). Causewayed enclosures are a class of monuments found across Southern Britain between the $38^{\text {th }}$ and the start of the $33^{\text {rd }}$ centuries cal BC, defined by one or more interrupted circuits of ditches (Whittle et al. 2011). I will discuss these sites, and Etton, more in a moment - it forms the next scale of assemblage - but here I want to look specifically at the act of deposition that included our pot. Running along the bottom of the ditch close to one of the causeways the deposit was formed of a fox mandible, the pot described above placed upside down, a decorated antler comb and a second (smaller) pottery bowl (Pryor 1998, 33). How can we think about these objects collectively - instead of individually - as an assemblage? One option would be to emphasise the potential symbolic meanings each of these might bring with them as I have done elsewhere (Harris $2005,44-5$ ). I would not want to dismiss such 
explanations. The point about assemblages is not to deny the importance of what a fox skull might represent, or whether an upturned pot might metaphorically stand for a skull or a head (Edmonds 1999; Harris 2005). Rather, this is not all such an assemblage is, assemblages are more-thanrepresentational (Harris 2016b; forthcoming; Pollard 2008). The process that produced this assemblage gathered these different material elements together; in turn they created new connections - new physical, material, connections - between them that had enunciative, meaningful consequences. These objects emerged out of particular sets of relationships, as we have discussed for one of the pots, and they brought all of these things to bear within the new assemblage. Thus whether or not Neolithic people conceptualised foxes as being 'powerful beings' (Pollard 2008, 57) is only part of the picture. This is an interesting question to investigate, but we can also attend to the material qualities of the fox skull that are not simply the outcome of what people in the past thought of it. It brings relationships to certain places and other animals into this assemblage and fixes them here. This particular set of objects came together through a specific historical practice of deposition, which clearly involved explicit choices being made by people involved with it. But the process also exceeded the choices they made, it brought together other connections and meanings, it drew on traditions of practice, it would have had affective consequences for others watching that might have been other than those that the choices of the people directly involved intended (cf. Harris \& Sørensen 2010). Assemblages always exceed themselves and bring about new capacities in the world to affect and be affected, because they are always becoming something else.

Figure 3: The Etton enclosure (after Pryor 1998, 100, fig. 103)

This act of digging the ditch and making this deposit is just one of many that made up the causewayed enclosure at Etton (fig. 3). Around $187 \mathrm{~m}$ in diameter, and formed of a single interrupted ditch of 14 segments, Etton is one of the smaller causewayed enclosures in England (Pryor 1998, xix). Initially constructed most likely between 3705 and 3670 cal BC (Whittle et al. 2011, 324), it was visited sporadically over the next four or five centuries (Beadsmore et al. 2010; Whittle et al. 2011). Throughout this, and indeed afterwards, Etton was in the process of becoming, of emerging as an assemblage, of which the deposit described above is just one component. Each visit involved digging; either initially to make the enclosure or later to create pits or recut the ditches. Into these spaces all manner of different things were deposited, incorporated into the assemblage of the enclosure. We have seen some of these in the deposit described above, but other features saw wooden objects placed in the ground, human skulls positioned to face causeways, polished stone axes inserted into pits and so on (Pryor 1998). Other objects were deliberately broken up and destroyed, deterritorialised as individual entities whilst simultaneously incorporated into the site. Many of the objects may have originated locally, but others had come all the way from North Wales, this was a site 
that incorporated both the close and the distant within its assemblage, as Pollard $(2008,52)$ rightly points out. Whilst the kinds of occupation and consumption that took place on the site might not have looked out of place at other Neolithic locales (Pryor 2014), it is clear that there was a particular rhythm to the way in which Etton became. People visited and left, territorialised and deterritorialised themselves from the assemblage. In comparison to other contemporary and local sites, Beadsmore et al (2010) note the relatively small amounts of deposition, given the length of time the site was in use for overall. This suggest a very particular pattern of engagement, one no doubt bound up in the fact that Etton would have been flooded for part of the year (Pryor 1998, 364). Indeed the material qualities of water are critical to the capacities of Etton as an assemblage. Not only did the ebb and flow of water condition how and when people came and went, it also ensured that the organic artefacts deposited in the western side of the enclosure remained part of the assemblage through into the present for archaeologists to recover.

Etton emerged therefore as a particular kind of assemblage through the historical process of a particular community of people, animals, place, water, things and plants coming together and moving apart in the centuries between 3700 and 3200 cal BC. Yet Etton was not alone, it did not emerge solely as a single example, the only causewayed enclosure. It was part of a wider historical process, another assemblage, involving enclosures across southern Britain. This process had its own temporal flow, its own process of becoming. As noted above, causewayed enclosures were not built in Britain before the middle of the $38^{\text {th }}$ century cal BC, and the process of building them has a widely shared pattern. Their construction peaks around 3650 cal BC before declining, reaching a low point with only a few enclosures constructed around $3575 \mathrm{cal} \mathrm{BC}$, only to rise again to a second peak around $3550 \mathrm{cal} \mathrm{BC}$, before declining once again (Whittle et al. 2011,698). Thus the local patterns of practice that produced Etton were part of much wider emergent assemblages across southern Britain at this time.

\section{Multiple scales at once}

In the manner in which I have described the three scales of assemblage so far - the pot, the deposit and the enclosure - the different scales have appeared to have been neatly nested within one another, like a Russian doll as Lesley McFadyen $(2008,307)$ evocatively puts it (cf. DeLanda 2006, 33). Things are far more complicated than that, however, and it is here we can see how an assemblage approach offers a different view of a multi-scalar archaeology. The first thing to note is that all our entities are simultaneously themselves operating at multiple scales (McFadyen 2008). So pot M79, is not only an assemblage in itself, it is also part of an assemblage of pots that existed over parts of Eastern England 
during the Early Neolithic that in the present we call Mildenhall Ware. It is also part of a wide-ranging assemblage we call pottery, that first appeared 20,000 years ago in China (Wu et al. 2012), and remains widely manufactured in different forms across the world today. A single pot, then, is both an assemblage in itself and part of countless other assemblages operating at multiple different scales simultaneously. These are all present within the material fabric of the object, and yet stretch out through space and time in different ways.

At the opposite end of the spectrum, whilst we have approached Etton as the largest scale, it was also at any one moment in its history an immediate and small-scale location, one place at one time. Thus we could, had we chosen to, treated this as a small-scale assemblage. As John Protevi points out in his multi-scalar study of the processes producing and affecting bodies in the contemporary world, each level includes all the different scales, what happens is that through our analysis the level of scale under study forms the 'highest point of intensity' $(2009, x v i)$. Thus the relationship between scales is not a simple one involving Euclidean notions of space and time, but is rather topological, or folded, interweaving within a single entity. They are, in this sense following Pauketat (2012; 2013), bundled. Like Deleuze' and Guattari's (2004) favourite the rhizome, there are connections within connections here, intersections and interweavings, that can be made manifest.

One objection to this may be to question the reality of these different assemblages. Whilst few archaeologists would deny that an individual pot has a reality as an entity in both the past and present, many have expressed quite reasonable scepticism about the reality of typological categories like 'Mildenhall Ware' or 'causewayed enclosure' for that matter. Do these scales of analysis have any reality to them, or are they simply things imposed by the archaeologist to bring order to the chaotic assemblages of the past (cf. Fowler 2013; Sørensen 2015)? Perhaps this is another example of working at the large-scale that brings with it unwanted reification? A key element of assemblage theory both for Deleuze and DeLanda is the commitment to realism (DeLanda 2002, 4). Assemblages really do exist in this ontology; they are not merely the products of human thought. Yet assemblage theory also rejects any notion of an essence, that there is some form of essential 'Mildenhall bowlness' that is shared by all the pots in this category (DeLanda 2010, 81) viii. We cannot simply define a set of taxonomic qualities - shape, size, material - that these pots have to share either, as we would quickly find (as with all typologies) that there are many examples that fit in this way but not that, that match in some ways but not others. Rather than focussing on the final, representational, form of these objects and trying to trace their similarities then, assemblage theory asks us once again to recognise how it is the processes of individuation that are shared, rather than the end results (Lucas 2012, 196). Of course for pottery typologies this process is one where the present (the work of archaeologists, 
microscopes, thin sections and so on) and the past (the work of clay, potters, temper and so on) are brought together - but are no less real for that (Fowler 2013) two typologically related pots share, therefore, is a historical process, one that took place with particular intensity through the middle centuries of the fourth millennium cal $\mathrm{BC}$, and in the $20^{\text {th }}$ and $21^{\text {st }}$ centuries AD. What is produced is a population of real entities - the pots themselves - and this population is as real an assemblage as any of the individual artefacts (Lucas 2012, 195). The critical realisation is that these scales of analysis are not simply the imposition of the analyst, though they do emerge in part from our work, but rather instead are always real and always relational (Fowler \& Harris 2015).

\section{Assemblages at the largest scale}

Can we push this further though? Can we go beyond the scale of a particular assemblage of monuments to think about the processes through which they, and all the other manifestations of monuments, houses, pottery and farming we see in Britain between 4100 and 2500 cal BC, emerged? Is there a reality to the whole of the British Neolithic as an assemblage? As Robb has perceptively argued, with reference to the broader European phenomenon, there has been 'an unstated insistence that if "the Neolithic" cannot be defined monothetically it has no analytical value' $(2013,672 ; 2014$; Thomas 2015, 1080-3)). Need this be the case? Recently Emilie Sibbesson and Andrew Jones (2013) have drawn on assemblages to explore how we can treat the period in Britain between 10,000 BC and $4000 \mathrm{BC}$ as a multiplicity. Drawing on this Deleuzian terminology they explore how multiple accounts can co-exist of this period, each with its own ontological reality, emphasising the varying pace of change over the long-term (Jones \& Sibbesson 2013, 164). This is an enormously promising approach, but I wonder if we can add to it to get more fully at how the changes in the centuries around $4000 \mathrm{BC}$ in Britain amount to something quite specific and significant, what DeLanda variously calls a bifurcation $(1997,15)$ or in his later work a phase transition $(2002$; Harris 2014b) . As John Barrett has shown, the transition to farming was a 'fundamental ecological change' $(2011,89)$. Yet at the same time, when we tease apart the differences between the Mesolithic and the Neolithic we can also trace much in the way of continuity as Jones and Sibbesson (2013) note, and as Vicki Cummings and I have argued elsewhere (Cummings \& Harris 2011; 2014). Equally, the changes that take place throughout the Neolithic cannot be denied (cf. Crellin this issue), not least the emergence and disappearance of monument types like causewayed enclosures that we discussed above ${ }^{\mathrm{xi}}$. Change and becoming are constant (Crellin this issue; Pauketat 2013, 55). Given this, how can we hold that there is anything shared in reality between the different communities that make up Neolithic Britain, things that make 
them 'Neolithic' and not 'Mesolithic' or 'Bronze Age' (cf. Robb 2013)? Can we comprehend what makes a community 'Neolithic' without resorting to a problematic notion of a shared and unified 'package' that, like the taxonomic typologies mentioned above, will always be insufficient? ${ }^{x i i}$ The answer requires us to explore one last element of assemblage theory.

A key element of Deleuzian thought is the manner in which it distinguishes between the virtual and the actual, with both being equally real (Deleuze 2004, 260; Lucas 2012, 167). The virtual captures the space of potentials that exist in the process of becoming through which things emerge. Different assemblages for Deleuze, therefore, have many virtual capacities in addition to their actualised properties (DeLanda 2006, 10). So, for example, our old friend pot M79 has many actualised properties - a weight that is the outcome of its relationship with gravity for example, or a colour that is the outcome of its making and firing processes - but it also has various virtual capacities that can be actualised through new relationships. It has the capacity to hold liquid, for example, or to be used for cooking, or to be broken into pieces and shared as tokens to create new relationships, or to be smashed up and employed as grog in further pots. These are real - in the sense that we cannot understand the role a pot like this played in the Neolithic if we do not consider them - but they are not actual. It is a virtual space like this, I suggest, that is shared by differing Neolithic communities in Britain. It is not the use of a particular kind of pot, or the building of particular monuments or even a reliance on farming that makes these societies Neolithic. These similarities, where they exist, form a package after the fact (Deleuze 2004, 147).

The specific arrangement of the virtual elements of an assemblage, the capacities it offers, its singularities or particular points of inflection (cf. DeLanda 2002, 61), allow us to identify what Deleuze and Guattari call a diagram (2004, 156; DeLanda 2016, chapter 5; cf. Normark 2010, 134). A diagram is the virtual - but remember always still real - element of an assemblage that can be actualised differently. The diagram of Neolithic Britain here is structured around the specific elements of pottery making, monument building, farming with certain crops, belief systems focused on ancestry, the power and potential of stone and the relations that link them (cf. Deleuze 2004, 260). Take a different period - like the Mesolithic - and some of these would be the same but others would not be. Different elements and relations apply (Thomas 2015, 1081). Thus what British Neolithic communities share is their emergence through a multi-scalar process shaped by this diagram. These create a whole host of ways in which the British Neolithic can or be actualised, from the settled villages of Late Neolithic Orkney, via the causewayed enclosures of Early Neolithic southern Britain or the henge monuments of the same region 1000 years later. Clearly, not all elements need be present in the same way for these societies to still be recognisably connected by this shared historical process. This emphasis on 
the process itself also emphasises that our diagram does not transcend the British Neolithic, but is rather imminent within it, thus we need make no appeal to any form of 'essence'. Here we see the 'envelope of possibilities', as Robb describes the Neolithic $(2013,667)$, given new ontological purchase as a virtual diagram ${ }^{\text {xiii. }}$

This matters because our ability to work at multiple scales requires us to be able to accord a reality to the things that exist, at both the largest and the smallest scales. If we want to understand the worlds of Neolithic Britain we have to be able to examine both detailed on the ground processes, the making of pots, the digging of a ditch, and the larger scale processes of which these are part. I have argued here that in order to understand the past we have to work at multiple scales, we have to understand how new kinds of ways of living, like the Neolithic, emerge from the very smallest of our assemblages up to the largest, and how these scales interweave in the same sets of materials. Understanding Neolithic pots as the products of real historical processes, as assemblages with their own lines of becoming, is essential to understanding the wider pattern of changes that took place in Britain throughout the $4^{\text {th }}$ and $3^{\text {rd }}$ millennia BC. At the same time, however, in order to understand pots in this period, we have to have a grip on the broader scale transformations and changes that were taking place, on the emergence of new kinds of community. This means we need to accord reality to entities at all scales in a manner that celebrates their ongoing becoming and their reality simultaneously (cf. Fowler and Harris 2015). Assemblages allow us to do just that.

\section{Conclusion}

Archaeologists spend a great deal of time discussing scale, arguing over whether small-scale intimate chronologies demand we focus more than ever on the day-to-day lives of people in the past (Whittle 2011), or whether we need to broaden our historical focus to include larger time frames (Robb 2007). We debate whether it is possible to ask questions of agency in the Lower Palaeolithic, or whether any discussion of widespread population growth in the Neolithic is inevitably reductive. Scholars have drawn on a variety of approaches to deal with these issues of scale, including Annales-influenced accounts such as time perspectivism. These approaches, however, have tended to treat each scale of time independently, and often in the end implicitly see the largest scale as the one that is most important. In this paper, I have argued that embracing assemblages opens up the potential for reconsidering the multiple scales at which the past operates. Crucially it neither renders the largescale as the place where all the really important stuff happens, nor does it dismiss this as simply the reification of small-scale practices where humans are the only critical actors. From the morphogenetic capacity of matter, via the practices of people and things together, to the historical processes that saw one kind of lifeway, one kind of ecology (sensu Barrett 2011), replaced by another, these different 
scales come together and interweave within an approach rooted in assemblages. This means we can rescue terms like the British Neolithic from being treated as totalising, essentialising, reified inventions and give them back their place within a transformed materialist ontology of assemblages. Critically these different scales are interwoven, not hierarchically situated, and it is in this way that assemblages, alongside related concepts like bundling, can offer us a radically new way of thinking about historical process and the transformation of the world.

\section{Acknowledgments}

Huge thanks are due to Yannis Hamilakis and Andy Jones for the invitation to speak at their excellent session at TAG in Manchester in 2014, and to the large number of people who have taken the time to help me to think through assemblage theory and the wider world of Deleuzian philosophy, most notably Pwyll ap Stifin, Bob Carter, Hannah Cobb, Rachel Crellin, Chris Fowler and - on numerous long car journeys - Ellie Rowley-Conwy. Excellent and useful comments on the article were provided by Rachel, Mark Gillings and two anonymous reviewers. All the usual disclaimers apply.

\section{Author Biography}

Oliver Harris is Associate Professor of Archaeology at the University of Leicester. His research focuses on archaeological theory and the British Neolithic. He is co-director of the Ardnamurchan Transitions Project, which looks at long-term change on the west coast of Scotland, and is co-author, along with John Robb and others, of The Body in History: Europe from the Palaeolithic to the Future (CUP) and, with Craig Cipolla, of Archaeological Theory in the New Millennium (Routledge, forthcoming). His research has been published in journals including World Archaeology, Archaeological Dialogues and American Anthropologist.

\footnotetext{
Notes

' Or at least is famously understood to have done so by archaeologists (cf. Olivier 2006, 90)

ii Harding argues for a genealogical approach tracing the histories of specific practices, institutions and material culture, focussing on the level of human experience $(2005,88)$. Whilst this approach is an excellent one for dealing with a specific scale of history, it does not really address the need to think about the past in a multiscalar fashion.

iii There are some interesting parallels to be drawn on another occasion between the concept of bundling and the recent emphasis placed on wrapping as articulated by Colin Richards (2013).

iv It is a topic for another debate but it is interesting to note that many of the popular anthropological analogues in archaeology in recent years - from Viveiros de Castro's (1998) perspectivism to Strathern's (1988) concepts of partibility - have a distinct, and often acknowledged, Deleuzian quality to them (see for example Viveiros de Castro 2009).

${ }^{\vee}$ DeLanda (2006) defines a further axis running between coding and decoding in order to deal with the specific properties of language, DNA and certain other elements of the world. Here I will stick with the original Deleuzian variation, and leave aside the complex relationship with coding and decoding (see Deleuze and Guattari 2004, 61).
} 


\footnotetext{
vi The terms territorialisation and deterritorialisation sound off putting, but in fact capture a critical element of the way in which these processes, for Deleuze and Guattari, are not just a gathering of things in geographic space and their inevitable breakup, but also a flow of substances coming together and moving apart topologically and intensively (that is with degrees of energy). Where possible I will limit the use of these terms in the rest of the paper except where these specific implications are being referred to (for more on this see DeLanda 2006, 10-2; Deleuze and Guattari 2004, 555-6).

vii This might be read as introducing a style/function or an ideal/material distinction into the debate. However, Deleuze and Guattari make clear in their emphasis on double articulation that the relationship between content and expression is much more complex than this, and always involves both form and substance on each side (see Deleuze and Guattari 2004, 44-82).

viii Here the difference between this and the Object Orientated Ontology of Graham Harman (2012) should be readily apparent (cf. Fowler and Harris 2015).

ix An argument that suggests that typologies - whether of pots or monuments - are simply imposed by archaeologists on to the material implicitly accepts a 'hylomorphic' model (Deleuze and Guattari 2004, 450, where form is always imposed from the outside on fundamentally chaotic matter (Protevi 2009, 15).

${ }^{x}$ And see Robb and Pauketat $(2013,25-6)$ on tipping points.

${ }^{x i}$ Nor of course should earlier changes within the Mesolithic be side-lined (e.g. Jones and Sibbesson 2013, 159)

xii Thomas (2003) has suggested the useful term repertoire for thinking about the reality of the Neolithic without reducing it to a package. The issue with repertoire is it tends to privilege the agency of people, rather than embracing the multiple constituents of the assemblages we have identified above. There is much more to be said about this and about the wider debates around the transition to the Neolithic in Britain, but space prevents their discussion here.

xiii Deleuze $(2004,263)$ stresses that the virtual is not the same as the possible. Making it merely possible removes a level of reality and creates a relationship of resemblance. For Deleuze, the singularities that create the potential for making specific kinds of pots do not resemble the pots themselves, but rather the potential for specific processes to emerge that differenciate these pots from others.
}

\section{References}

Alberti, B. \& A.M. Jones, 2013. Archaeology after interpretation, in Archaeology after interpretation: returning materials to archaeological theory, eds. B. Alberti, A.M. Jones \& J. Pollard. Walnut Creek, CA: Left Coast Press, 15-35.

Bailey, G., 1981. Concepts, timescales and explanations in economic prehistory, in Economic archaeology, eds A. Sheridan \& G. Bailey. Oxford: British Archaeological Reports, 97-117.

Bailey, G., 1987. Breaking the time barrier. Archaeological Review from Cambridge 6, 5-20.

Bailey, G., 2007. Time perspectives, palimpsests and the archaeology of time. Journal of Anthropological Archaeology 26, 198-223.

Barrett, J.C., 2011. The Neolithic revolution: an ecological perspective, in Dynamics of Neolithisation in Europe: Studies in Honour of Andrew Sherratt, eds. A. Hadjikoumis, E. Robinson \& S. Viner. Oxford: Oxbow, 66-89.

Beadsmore, E., D. Garrow \& M. Knight, 2010. Refitting Etton: space, time, and material culture within a causewayed enclosure in Cambridgeshire. Proceedings of the Prehistoric Society 76, 115-34.

Bennett, J., 2010. Vibrant Matter: a political ecology of things. London: Duke University Press.

Braudel, F., 1972. The Mediterranean and the Mediterranean World in the Age of Phillip II. London: Collins.

Cobb, H. \& K. Croucher, 2014. Assembling archaeological pedagogy. A theoretical framework for valuing pedagogy in archaeological interpretation and practice. Archaeological Dialogues 21(2), 197-216. 
Cummings, V. \& O.J.T. Harris, 2011. Animals, People and Places: the Continuity of Hunting and Gathering Practices Across the Mesolithic-Neolithic Transition in Britain. European Journal of Archaeology 14(3), 361-82.

Cummings, V. \& O.J.T. Harris, 2014. The continuity of hunting and gathering in the Neolithic and beyond in Britain and Ireland, in The Oxford Handbook of the Archaeology and Anthropology of Hunter-Gatherers, eds. V. Cummings, P. Jordan \& M. Zvelebil. Oxford: Oxford University Press, 824-37.

DeLanda, M., 1997. A thousand years of non-linear history. New York, NY: Zone Books.

DeLanda, M., 2002. Intensive Science and Virtual Philosophy. London: Continuum.

DeLanda, M., 2006. A New Philosophy of Society: Assemblage Theory and Social Complexity. London: Continuum.

DeLanda, M., 2007. Material elegance. Architectural Design 77(1), 18-23.

DeLanda, M., 2010. Deleuze: history and science. Dresden: Atropos Press.

DeLanda, M., 2016. Assemblage theory. Edinburgh: Edinburgh University Press.

Deleuze, G., 2004. Difference and repitition. London: Bloomsbury.

Deleuze, G. \& F. Guattari, 2004. A Thousand Plateaus: Capitalism and Schizophrenia. London: Continuum.

Dewsbury, J.-D., 2011. The Deleuze-Guattarian assemblage: plastic habits. Area 43(2), 148-53.

Due, R., 2002. Deleuze, London: Polity.

Edmonds, M., 1999. Ancestral geographies of the Neolithic: landscapes, monuments and memories. London: Routledge.

Fowler, C., 2013. The emergent past: a relational realist archaeology of Early Bronze Age mortuary practices., Oxford: Oxford University Press.

Fowler, C. \& O.J.T. Harris, 2015. Enduring relations: exploring a paradox of New Materialism. Journal of Material Culture 20(2), 127-48.

Garrow, D., 2013. Odd deposits and average practice. A critical history of the concept of structured deposition. Archaeological Dialogues 19(2), 85-115.

Gosden, C., 2013. Long-term history: a short response, in Big histories, human lives: tackling the problem of scale in archaeology, eds. J.E. Robb \& T.R. Pauketat. Sante Fe, NM: SAR Press, 207-14.

Hamilakis, Y., 2014. Archaeology and the senses: human experience, memory and affect. Cambridge: Cambridge University Press.

Harding, J., 2005. Rethinking the great divide: long-term structural history and the temporality of gthe event. Norwegian Archaeological Review 38, 88-101.

Harman, G., 2012. The quadruple object. Winchester: Zero Books.

Harris, O.J.T., 2005. Agents of identity: performative practice at the Etton causewayed enclosure, in Elements of being: mentalities, identities and movements, eds. D. Hofmann, J. Mills \& A. Cochrane. Oxford: BAR, 40-9.

Harris, O.J.T., 2013. Relational communities in prehistoric Britain, in Relational archaeologies: humans, animals, things, ed. C. Watts. London: Routledge, 173-89.

Harris, O.J.T., 2014a. (Re)assembling communities. Journal of Archaeological Method and Theory 21, 76-97.

Harris, O.J.T., 2014b. Revealing our vibrant past: science, materiality and the Neolithic, in Early farmers: the view from archaeology and science, eds. A. Whittle \& P. Bickle. Oxford: Proceedings of the British Academy, 327-45.

Harris, O.J.T., 2016a. Affective architecture in Ardnamurchan: assemblages at three scales, in Elements of Architecture: Assembling Archaeology, Atmosphere and the Performance of Building Space, eds. M. Bille \& T.F. Sørensen. London: Routledge, 195-212.

Harris, O.J.T., 2016b. Becoming post-human: identity and the ontological turn, in Creating Material Worlds: Theorising Identity in Archaeology, eds. E. Pierce, A. Russell, A. Maldonado \& L. Campbell. Oxford: Oxbow, 17-37. 
Harris, O.J.T., forthcoming. More than representation: multi-scalar assemblages and the Deleuzian challenge to archaeology. History of the Human Sciences.

Harris, O.J.T. \& T.F. Sørensen, 2010. Rethinking Emotion and Material Culture. Archaeological Dialogues 17(2), 145-63.

Jervis, B., 2014. Pottery and social life in medieval England, Oxford: Oxbow.

Jones, A.M., 2012. Prehistoric Materialities: becoming material in prehistoric Britain and Ireland. Oxford: Oxford University Press.

Jones, A.M. \& E. Sibbesson, 2013. Archaeological complexity: materials, multiplicity, and the transitions to agriculture in Britain, in Archaeology after interpretation: returning materials to archaeological theory, eds. B. Alberti, A.M. Jones \& J. Pollard. Walnut Creek, CA: Left Coast Press, 151-72.

Kinnes, I., 1998. The pottery, in Etton: excavations at a Neolithic Causewayed Enclosure near Maxey Cambridgeshire, 1982-7, F. Pryor. London: English Heritage, 161-214.

Knapp, A.B., 1992. Archaeology and Annales: time, space, and change, in Archaeology, Annales and Ethnohistory, ed. A.B. Knapp. Cambridge: Cambridge University Press, 1-21.

Lucas, G., 2012. Understanding the archaeological record. Cambridge: Cambridge University Press.

Normark, J., 2010. Involutions of materiality: operationalising a neo-materialist perspective through the causeways at Ichmul and Yo'okop. Journal of Archaeological Method and Theory 17, 132-73.

McFadyen, L., 2008. Building and architecture as landscape practice, in Handbook of landscape archaeology, eds. B. David \& J. Thomas. Walnut Creek, CA, Left Coast Press, 307-14.

Olivier, L., 2006. The greatest harmony is born of differences. Norwegian Archaeological Review 39, 89-93.

Olsen, B., M. Shanks, T. Webmoor \& C.L. Witmore, 2012. Archaeology: the discipline of things, Berkeley. CA: University of California Press.

Pauketat, T.R., 2013a. An archaeology of the cosmos: rethinking agency and religion in ancient America. London: Routledge.

Pauketat, T.R., 2013b. Bundles of/in/as/ time, in Big histories, human lives: tackling the problem of scale in archaeology, eds. J.E. Robb \& T.R. Pauketat. Sante Fe, NM: SAR Press, 35-56.

Pollard, J., 2008. Deposition and material agencyin the Early Neolithic of Southern Britain, in Memory work: archaeologies of material practices, eds. B.J. Mills \& W.H. Walker. Sante Fe, NM: SAR Press, 41-59.

Protevi, J. 2009. Poltical affect: connecting the social and the somatic. Minneapolis, MN: University of Minnesota Press.

Pryor, F., 1998. Etton: excavations at a Neolithic causewayed enclosure near Maxey, Cambridshire 1982-7. London: English Heritage.

Pryor, F., 2014. Home, London: Allen Lane.

Richards, C., (ed.) 2013. Building the great stone circles of the north. Oxford: Windgather Press.

Robb, J.E., 2007. The Early Mediterranean Village: Agency, Material Culture, and Social Change in Neolithic Italy. Cambridge: Cambridge University Press.

Robb, J.E., 2008. Tradition and agency: human body representations in later prehistoric Europe. World Archaeology 40, 332-53.

Robb, J.E., 2012. History in the body: the scale of belief, in Big histories, human lives: tackling problems of scale in archaeology, eds. J.E. Robb \& T.R. Pauketat. Santa Fe: SAR Press, 77100.

Robb, J.E., 2013. Material culture, landscapes of action, and emergent causation: a new model for the origins of the European Neolithic. Current Anthropology 54, 657-83.

Robb, J.E., 2014. The future Neolithic: a new research agenda, Early farmers: the view from archaeology and science, eds. A. Whittle \& P. Bickle. Oxford: Proceedings of the British Academy, 21-38. 
Robb, J.E. \& O.J.T. Harris, 2013. The Body in History: Europe from the Palaeolithic to the Future. Cambridge: Cambridge University Press.

Robb, J.E. \& T.R. Pauketat, 2013. From moments to millennia: theorising scale and change in human history, in Big histories, human lives: tackling the problem of scale in archaeology, eds. J.E. Robb \& T.R. Pauketat. Sante Fe, NM: SAR Press, 3-33.

Sørensen, M.L.S. 2015. 'Paradigm lost' - on the state of typology within archaeological theory, in Paradigm found: archaeological theory past, present and future. Essays in honour of Evžen Neustupný, eds. K. Kristiansen, L. Šmejda \& J. Turek. Oxford: Oxbow, 84-94.

Strathern, M., 1988. The Gender of the Gift: Problems with Women and Problems with Society in Melanesia. Cambridge: Cambridge University Press.

Thomas, J., 2003. Thoughts on the repacked Neolithic revolution. Antiquity 77, 67-74.

Thomas, J., 2013. The birth of Neolithic Britain: an interpretive account. Oxford: Oxford University Press.

Thomas, J., 2015. What do we mean by 'Neolithic societies'?, in The Oxford Handbook of Neolithic Europe, eds. C. Fowler, J. Harding \& D. Hofmann. Oxford: Oxford University Press, 10731091.

Viveiros de Castro, E., 1998. Cosmological deixis and Amerindian perspectivism. Journal of the Royal Anthropological institute 4, 469-88.

Viveiros de Castro, E., 2009. Intensive filiation and demonic alliance, in Deleuzian Intersections: science, technology, anthropology, eds. C.B. Jensen \& K. Rödje. Oxford: Berghahn, 219-54.

Whittle, A., 2003. The Archaeology of People: Dimensions of Neolithic Life. London: Routledge.

Whittle, A., 2011. Grand narratives and shorter stories, in Dynamics of Neolithisation in Europe: Studies in Honour of Andrew Sherratt, eds. A. Hadjikoumis, E. Robinson \& S. Viner. Oxford: Oxbow, 10-24.

Whittle, A., F. Healy \& A. Bayliss, 2011. Gathering Time: Dating the Early Neolithic Enclosures of Southern Britain and Ireland. Oxford: Oxbow.

Witmore, C.L., 2014. Archaeology and the New Materialisms. Journal of Contemporary Archaeology 1(2), 203-46.

Wu, X., C. Zhang, P. Goldberg, D. Cohen, Y. Pan, T. Arpin \& O. Bar-Yosef, 2012. Early pottery at 20,000 years ago in Xianrendong Cave, China. Science 336, 1696-700. 